\title{
Crosstalk between hepatocyte growth factor and integrin signaling pathways
}

\author{
Po-Chao Chan, Shu-Yi Chen, Chun-Hwa Chen \& Hong-Chen Chen* \\ Department of Life Sciences and Graduate Institute of Biomedical Sciences, National Chung Hsing Univer- \\ sity, 250 Kuo-Kuang road, Taichung, 40227, Taiwan \\ (C) 2006 National Science Council, Taipei
}

Key words: HGF, Met, integrin, FAK, crosstalk

\begin{abstract}
Summary
Most types of normal cells require integrin-mediated attachment to extracellular matrix to be able to respond to growth factor stimulation for proliferation and survival. Therefore, a consensus that integrins are close collaborators with growth factors in signal transduction has gradually emerged. Some integrins and growth factor receptors appear to be normally in relatively close proximity, which can be induced to form complexes upon cell adhesion or growth factor stimulation. Moreover, since integrins and growth factor receptors share many common elements in their signaling pathways, it is clear tzhat there are many opportunities for integrin signals to modulate growth factor signals and vice versa. Increasing evidence indicates that integrins can crosstalk with receptor tyrosine kinases in a cell- and integrin-type-dependent manner through a variety of specific mechanisms. This review is intended specifically for summarizing recent progress uncovering how the hepatocyte growth factor receptor c-Met coordinates with integrins to transmit signals.
\end{abstract}

\section{Introduction}

Cell adhesion to extracellular matrix (ECM) is a prerequisite for cell proliferation and survival [1]. The effects of ECM on cells are mainly mediated by the integrins, a large family of cell surface receptors that bind to ECM components, organize the cytoskeleton, and activate intracellular signaling pathways. Each integrin is composed of two subunits: $\alpha$ and $\beta$. In mammals, $18 \alpha$ and $8 \beta$ subunits associate in various combinations to form 24 integrins that can bind to distinct, although partially overlapping, subsets of ECM proteins [2, 3]. Several lines of evidence indicate that pathways for integrin signaling and growth factor signaling are mechanistically linked. First, cell adhesion to ECM is required for cells to respond to certain

*To whom correspondence should be addressed. Tel: + 886-4 22854922; Fax: +886-4-22853469; E-mail: hochen@nchu.edu.tw growth factors [1]. Second, integrin-mediated cell adhesion and motility can be modulated by growth factors [4-6]. Third, many of the signaling molecules associated with growth factor receptors, such as Src, are also present in integrin complexes at focal adhesions [7]. Actually, many previous studies suggested that integrins can crosstalk with receptor tyrosine kinases in a cell- and integrintype-dependent manner through a variety of specific mechanisms [8, 9].

Most integrins activate focal adhesion kinase (FAK) which transduces signals to the downstream through its interaction with several intracellular signaling molecules, including the Src family kinases, PI3K, phospholipase C- $\gamma 1$, Grb2, $\mathrm{p} 130^{\mathrm{Cas}}$, and paxillin $[10,11]$. FAK is well known for its pivotal role in the control of integrinmediated cell functions, including cell migration, cell cycle progression, and cell survival. However, increasing evidence has also suggested that FAK 
may be a point of convergence of integrin and growth factor signaling pathways. In addition to cell adhesion, a number of growth factors were shown to stimulate the tyrosine phosphorylation of FAK [12-14] through activation of the Src family kinases [14] and/or physical association of FAK with the growth factor receptors [15]. The phosphorylation and activation of FAK in response to growth factor stimulation facilitate its association with other signaling molecules, thereby leading to amplification of downstream signals $[14$, $15]$.

Hepatocyte growth factor (HGF), also known as scatter factor, is a mesenchymally derived factor that elicits multiple cellular responses, including proliferation, migration, and morphogenesis, on various types of cells, [16-18]. The diverse biological effects of HGF are transmitted through activation of its transmembrane receptor encoded by the c-met proto-oncogene [19]. The Met receptor is a heterodimer composed of a $45-\mathrm{kDa} \alpha$ chain that remains entirely extracellular, and a $145-\mathrm{kDa}$ $\beta$ chain that traverses the plasma membrane and contains the intracellular tyrosine kinase domain [20, 21]. Upon HGF binding, the intrinsic tyrosine kinase of the receptor is activated resulting in autophosphorylation on specific tyrosine residues in the $\beta$ chain $[22,23]$. Two tyrosine residues in the $\mathrm{COOH}$-terminus of the $\beta$ chain (Tyr-1349 and Tyr-1356) are required for all biological activities of the receptor [24, 25] and serve as docking sites for the Grb2-associated binder-1 (Gab1) docking protein $[26,27]$ and multiple Src homology 2 and phosphotyrosine binding domain-containing proteins $[28,29]$. In human cancers, the c-met gene has frequently been found to be amplified, mutated or overexpressed [17, 18].

Recent studies indicated that HGF signaling can crosstalk with integrin signaling through at least three modes. First, the Met receptor physically associates with integrins at the plasma membrane where they reciprocally regulate each other. Second, HGF and integrin signaling pathways are converged to some intracellular signaling molecules, such as FAK and Src, which further transduce signals to the downstream. Thirdly, HGF signaling leads to alteration in the expression of integrins that is essential for the biological activities of HGF.

\section{Met-integrin interplay at the plasma membrane}

The HGF receptor c-Met engages in reciprocal regulation with integrins at the plasma membrane (Figure 1). The $\alpha 6 \beta 4$ integrin has been shown to cooperate with the function of HGF and its receptor c-Met in carcinoma cells, resulting in enhanced invasive growth [30]. Upon c-Met activation, $\alpha 6 \beta 4$ integrin physically associates with
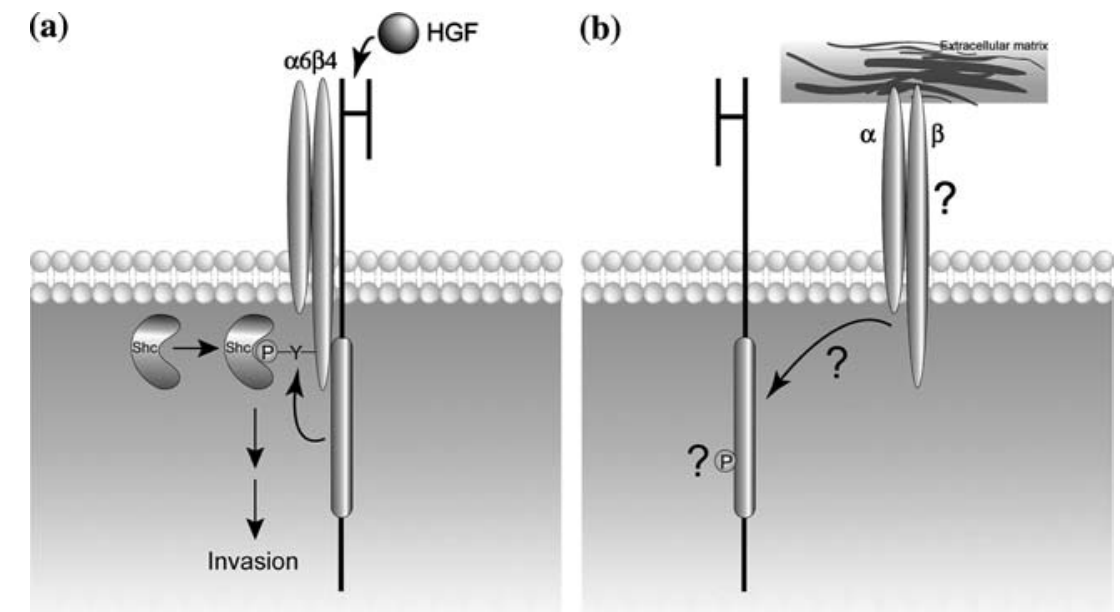

Figure 1. c-Met and integrin interplay at the plasma membrane. (a) In response to HGF stimulation, $\alpha 6 \beta 4$ integrin physically associates with c-Met and undergoes tyrosine phosphorylation on the $\beta 4$ cytoplasmic domain, which subsequently forms a complex with Shc and PI3K, thereby potentiating Ras and PI3K signaling. The interaction of the $\beta 4$ cytoplasmic domain with the adaptor protein Shc is required for HGF-induced invasion of cancer cells. (b) Ligand-independent activation of c-Met by cell adhesion. However, integrin specificity and the mechanism responsible for this form of c-Met activation remain unclear. 
c-Met and undergoes tyrosine phosphorylation on the $\beta 4$ cytoplasmic domain, which subsequently forms a complex with Shc and PI3K, thereby potentiating Ras and PI3K signaling (Figure 1a). The $\alpha 6 \beta 4$ integrin is somewhat special among other integrins in that the $\beta 4$ subunit contains an unusually long cytoplasmic domain, which provides this integrin with additional She binding sites to the Met- $\alpha 6 \beta 4$ receptor complex, thereby amplifying Met signaling above a critical threshold for invasive behavior. The extracellular domain of the $\beta 4$ integrin is not required for its cooperation with the activated c-Met, suggesting an adhesionindependent role for this integrin. In addition, the $\alpha 6 \beta 4$ integrin also associates with the epidermal growth factor (EGF) receptor family member ErbB2 in carcinoma cells [31]. Again, the $\beta 4$ cytoplasmic domain as a monomer is necessary and sufficient to associate with ErbB2, whereas the extracellular domain, and hence matrix binding, is not required for this function [32].

Integrins, on the other hand, can induce various growth factor receptors to undergo ligand-independent activation, at least to the extent of enhanced tyrosine phosphorylation after cell adhesion [33-37]. It has been shown that the majority of c-Met in certain tumor cells can be activated by cell attachment, presumably through integrins, in the complete absence of HGF [34] (Figure 1b). Overexpression of c-Met appears to be a prerequisite for its activation by cell adhesion. Neither the integrity of the actin cytoskeleton nor FAK activation is required for this form of c-Met activation [34]. Moreover, overexpression of c-Met in hepatocytes of mice enables ligand-independent activation of the receptor that leads to hepatocellular carcinoma [38]. However, integrin specificity and the mechanism responsible for the ligandindependent activation of c-Met remain unclear. A previous study done by Moro et al. [39] provides a possible explanation for how integrin-mediated adhesion could induce phosphorylation of growth factor receptors. They found that upon cell adhesion, $\alpha \mathrm{v} \beta 3$ and $\beta 1$ integrins associate with EGF receptors in a complex with p130Cas and c-Src, both of which are crucial for integrin-induced phosphorylation of EGF receptors. Notably, the pattern of EGF receptor phosphorylation induced by integrins is unique, compared to the pattern after EGF-induced autophosphorylation. They found that tyrosine 1148 is unphosphorylated, a key residue that is normally phosphorylated after EGF stimulation. However, four other tyrosines are phosphorylated normally [39].

Intracellular signaling, called "inside-out" signaling, controls the interaction between integrins and ligands $[5,6]$. This cell type-specific process modulates integrin affinity, which is caused by a conformational change and modulation of lateral diffusion and/or integrin clustering. HGF has been shown to activate integrin $\alpha \mathrm{v} \beta 3$ in epithelial cells [40], $\alpha \mathrm{v} \beta 3$ and $\alpha 5 \beta 1$ in endothelial cells [41], LFA-1 $(\alpha \mathrm{M} \beta 2)$ in colon cancer cells and neutrophils [42, 43], and $\alpha 4 \beta 1$ in B cells [44, 45]. In contrast, HGF was reported to inhibit $\alpha_{\mathrm{IIb}} \beta 3$ activation in platelet cells [46]. Nevertheless, the mechanisms underlying those phenomena are unclear.

\section{FAK serves as a point of convergence of HGF and integrin signaling pathways in the cytoplasm}

Although a number of growth factors are known to modulate cell motility, HGF is unique because of the intensity with which it stimulates cell motility and induces epithelial-mesenchymal transition. Since FAK is well known for its pivotal role in regulating integrin-mediated cell motility [11], it was reasonable to speculate that FAK is involved in HGF signaling and plays a role in HGFstimulated cell motility. It is now known that HGF rapidly induces an increase in FAK phosphorylation through at least two mechanisms: one is indirectly mediated by Src [14] and the other is directly phosphorylated by c-Met (Figure 2a). The maximal activation of FAK upon HGF stimulation may be reached only when both Met-FAK and Met-Src-FAK pathways are activated. The activated FAK functions as a signaling platform to potentiate HGF-elicited signals, thereby contributing to HGF-stimulated cell motility [47] and cell invasion [48]. In accordance with the observation that increased level of FAK contributes to a more aggressive phenotype in tumors [49-51], overexpression of FAK renders cultured epithelial cells susceptible to cellular transformation by HGF stimulation [48]. Recently, we found that FAK directly interacts with phosphorylated c-Met upon HGF stimulation. Under certain circumstances, for example, when c-Met is overexpressed and/or constitutively activated, Met-FAK interaction 
(a)

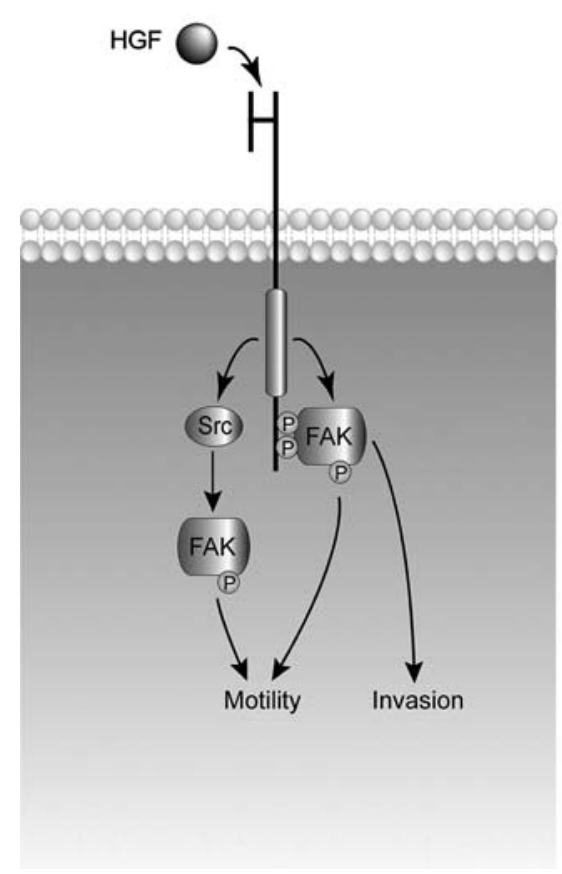

(b)

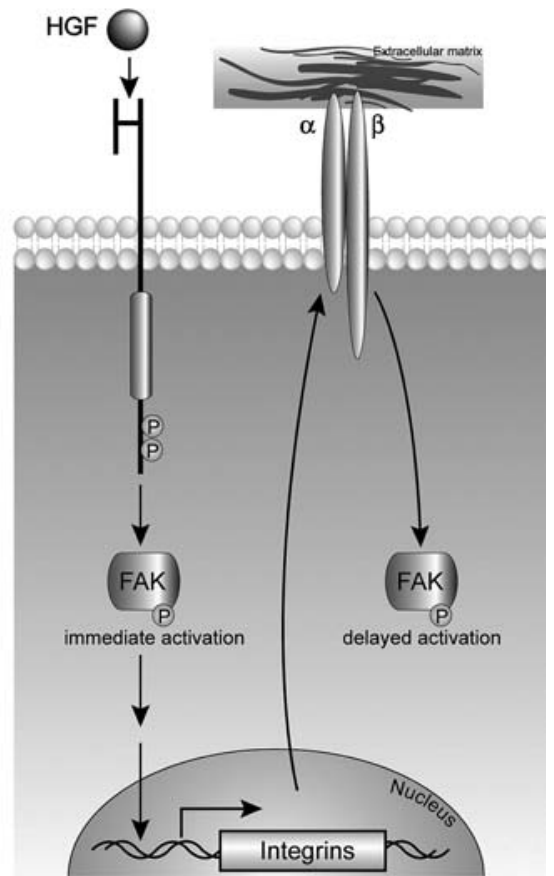

Figure 2. FAK serves as a point of convergence of HGF and integrin signaling pathways in the cytoplasm. (a) HGF rapidly induces an increase in FAK phosphorylation through at least two modes: Met-Src-FAK and Met-FAK pathways. The activated FAK functions as a signaling platform to potentiate HGF-elicited signals, thereby contributing to HGF-stimulated cell motility and cell invasion. Note that the ability of FAK to promote HGF-stimulated invasion largely relies on its direct interaction with Met. (b) The effect of HGF on FAK phosphorylation may be through an immediate (integrin-independent) response and a delayed (integrin-dependent) response. The de novo expression of integrins induced by HGF may contribute to the delayed phase of FAK phosphorylation.

could become constitutive independently of HGF stimulation. This interaction occurs through the band 4.1 and ezrin/radixin/moesin homology domain (FERM domain) of FAK and the phosphorylated Tyr-1349 and Tyr-1356 of c-Met. Notably, the ability of FAK to promote HGFstimulated cell invasion largely depends on its direct interaction with Met.

The immediate response of FAK to HGF stimulation occurs in close proximity to c-Met as described above, which is independent of integrinmediated cell adhesion [14]. Since HGF is known to selectively increase the expression of certain integrins such as integrin $\alpha 2$ and $\alpha 3$ [47, 52, 53], it is plausible that increased levels of integrins may further lead to the activation of FAK following cell adhesion to ECM proteins. It is therefore likely that the effect of HGF on FAK activation can be through an immediate (integrin-independent) response and a delayed (integrin-dependent) response (Figure 2b). The sustained activations of FAK and other signaling molecules such as ERK (see below) are critical for the long-term cellular responses to $\mathrm{HGF}$. For instance, the scatter response of Madin-Darby canine kidney (MDCK) cells to HGF stimulation is a dynamic process usually initiated by membrane ruffling and centrifugal spreading of cell colonies (after 1-3 h). Subsequently, some cells within the colony begin to detach from their neighboring cells (after 3-6 h) and exhibit a shape resembling that of motile fibroblasts. These cells continue to migrate (from $6 \mathrm{~h}$ ), finally leading to a "scatter" phenomenon [47].

\section{HGF induces the expression of integrins via sustained activation of ERK}

Although the role of ERK (extracellular signalregulated kinase) singling pathway in cell proliferation has been well established [54], increasing 
(a)

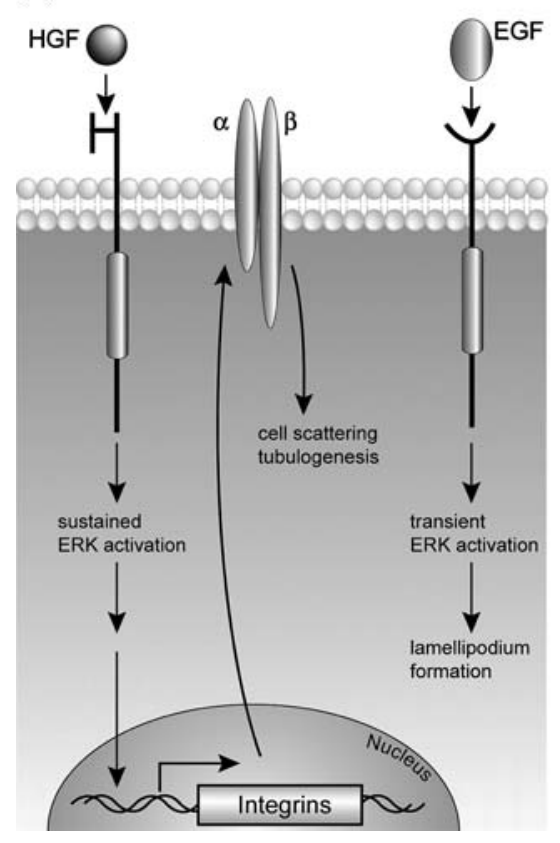

(b)

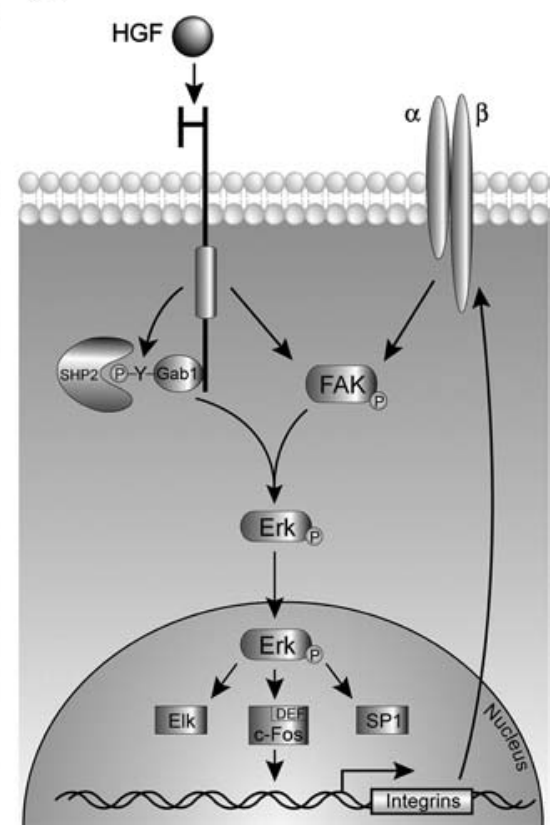

Figure 3. Sustained activation of ERK induced by HGF results in the expression of integrins. (a) In MDCK cells, sustained activation of ERK and its persistent nuclear retention lead to expression of several genes such as integrins. The induction of $\alpha 2 \beta 1$ integrins is essential for HGF to induce cell scattering and tubulogenesis. For the same type of cells, EGF induces transient activation of ERK and fails to induce such cellular responses. (b) A proposed model for HGF to induce sustained activation of ERK and its persistent retention in the nucleus. Evidence suggests that FAK and Gabl may function as a platform to amplify signals, leading to sustained ERK activation. In the case of Gab1, its prolonged phosphorylation and association with the tyrosine phosphatase SHP-2 are essential for sustained activation of ERK. Active ERKs translocate to the nucleus where they phosphorylate immediate early gene products such as Sp1, Elk, and c-Fos. Carboxy-terminal phosphorylation stabilizes c-Fos and primes additional phosphorylation by exposing a binding site for ERK, termed the DEF domain. Binding of ERK to the DEF domains of c-Fos and/or other immediate early gene products may cause accumulation of ERK in the nucleus, thereby leading to the expression of target genes.

evidence suggests that the duration of ERK activation may be a crucial determinant for cells to proceed certain cellular functions other than proliferation [55]. For example, in phaeochromocytoma PC12 cells, sustained, but not transient, activation of ERK precedes differentiation into sympathetic-like neurons [56]. Likewise, HGF has been reported to induce sustained activation of ERK [52, 57-59]. In MDCK cells, sustained activation (at least for $12 \mathrm{~h}$ ) of ERK is required for $\mathrm{HGF}$ to induce cell scattering $[52,58]$. In contrast, EGF induces transient activation of ERK in MDCK cells, which declines by $30 \mathrm{~min}$ and returns to the basal level by $1 \mathrm{~h}$ post stimulation. Whereas HGF induces scatter response of MDCK cells, EGF only induces lamellipodium formation around the cell colony and fails to trigger cell scattering (Figure 3a). The sustained activation of ERK induced by HGF coincides with its persistent nuclear accumulation, which results in the expression of several genes such as integrins $\alpha 2$ and $\alpha 3$ and matrix metalloproteinase- $9[52,58]$. The inductions of integrin $\alpha 2 \beta 1$ and metalloproteinase- 9 are required for $\mathrm{HGF}$-induced cell scattering $[52,58]$. In addition, the up-regulations of integrins $\alpha 2 \beta 1$ and $\alpha 3 \beta 1$ are important for HGF-induced branching tubulogenesis in threedimensional collagen gels [53, 60, 61].

The increased expression of integrin $\alpha 2$ by $\mathrm{HGF}$ is a consequence of increased integrin $\alpha 2$ mRNA likely due to transcriptional activation [52]. Characterization of the 5 '-flanking region of human integrin $\alpha 2$ gene reveals that the promoter region contains consensus binding sites for several transcription factors, including $\mathrm{Sp} 1$, AP1, and AP2 [62]. The binding of phosphorylated Sp1 to two Sp1 binding sites in the core promoter region of human integrin $\alpha 2$ gene is required for full promoter activity [63]. It is known that ERK activation increases AP1 activity via c-Jun activa- 
tion and increased c-Fos synthesis, leading to an increase in c-Jun/c-Fos heterodimerization and DNA binding [64, 65]. In addition, ERK can phosphorylate Sp1 and induce its DNA binding activity [66]. Therefore, it is possible that persistent nuclear accumulation of ERK induced by HGF stimulation may target $\mathrm{Sp} 1$ and AP1, leading to activation of integrin $\alpha 2$ gene.

The mechanism by which HGF induces sustained activation of ERK and its persistent nuclear retention is unclear. Since integrin-mediated cell adhesion to ECM proteins activates the ERK signaling pathway and often potentiates the effect of growth factors on activating the pathway [67], the de novo expression of integrins induced by HGF may contribute to the sustained phase of ERK activation (Figure $3 b$ ). It was proposed that prolonged phosphorylation of the major Met-docking protein Gab1 and its association with the tyrosine phosphatase SHP-2 are required for sustained activation of ERK and for epithelial morphogenesis downstream from c-Met [59]. Overexpression of FAK and, presumably, its interaction with Met potentiates the duration of ERK activation [48]. Moreover, York et al. [56] showed that in PC12 cells, the early phase of nerve growth factorstimulated ERK activation is mediated by the small GTPase Ras, but the sustained phase of the ERK activation is due to activation of another small GTPase, Rap1. The role of Rap1 in HGFinduced sustained activation of ERK remains to be clarified. It was reported that the immediate early gene product c-Fos functions as a sensor for ERK signal duration [68]. When ERK activation is transient, its activity declines before the c-Fos protein accumulates, and under such condition c-Fos is unstable. However, when ERK signaling is sustained, it persistently accumulates in the nucleus and phosphorylates c-Fos. Carboxyterminal phosphorylation stabilizes c-Fos and primes additional phosphorylation by exposing a binding site for ERK, termed the DEF domain. Interestingly, putative DEF domains are also found in other AP-1 proteins, such as Fra-1, Fra-2, JunB, and JunD [68]. It has been shown that HGF induces increased and prolonged expression of c-Fos [58]. It remains to be determined whether the interaction of ERK with c-Fos or other DEF domain-containing proteins in the nucleus is essential for its persistent nuclear retention.

\section{Perspectives}

There has been substantial recent progress in understanding how integrin and the c-Met receptor collaborate to transmit signals and thereby coordinate regulate cell behavior. The picture emerging from these studies is that the crosstalk networks between signaling pathways from both types of cell surface receptors are intertwined at various cellular locations through various modes. Nonetheless, several open questions remain to be answered. At the plasma membrane, it will be important to determine which types of integrins are involved in ligand-independent activation of c-Met and the underlying mechanism for the activation. In the cytoplasm, some molecules, e.g. FAK, are engaged in both integrin and HGF signaling pathways. Does integrin compete with c-Met for FAK? Do signals propagated by reciprocal regulation between $\mathrm{Met}$ and FAK produce unique biological effects? In the nucleus, it will be important to determine the mechanism by which HGF induces persistent nuclear retention of ERK. What are the targets of transient vs. sustained activation of ERK? Understanding these circuits in detail should shed light on a variety of pathological states as well as delineate more effective strategies for future therapeutic intervention.

\section{Acknowledgments}

Work in the authors' laboratory is supported by the National Science Council, Taiwan, through grants NSC94-2320-B-005-003 and NSC94-2320B-005-010.

\section{References}

1. Frich S.M. and Ruoslahti E., Integrins and anoikis. Curr. Opin. Cell Biol. 5: 701-706, 1997.

2. Giancotti F.G. and Ruoslahti E., Integrin signaling. Science 285: 1028-1032, 1999.

3. Hynes R.O., Integrins: bidirectional, allosteric signaling machines. Cell 110: 673-687, 2002.

4. Klemke R.L., Yebra M., Bayna E.M. and Cheresh D.A., Receptor tyrosine kinase signaling required for integrin alpha $\mathrm{v}$ beta 5 -directed cell motility but not adhesion on vitronectin. J. Cell Biol. 127: 859-866, 1994.

5. O’Toole T.E., Katagiri Y., Faull R.J., Peter K., Tamura R., Quaranta V., Loftus J.C., Shattil S.J. and Ginsberg M.H., Integrin cytoplasmic domain mediate inside-out signal transduction. J. Cell Biol. 124: 1047-1059, 1994. 
6. Bazzoni G. and Hemler M.E., Are changes in integrin affinity and conformation overemphasized?. Trends Biochem. Sci. 23: 30-34, 1998.

7. Clark E.A. and Brugge J.S., Integrins and signal transduction pathways: the road taken. Science 268: 233-239, 1995.

8. Schwartz M.A. and Baron V., Interactions between mitogenic stimuli, or, a thousand and one connections. Curr. Opin. Cell Biol. 11: 197-202, 1999.

9. Yamada K.M. and Danen E.H.J., Integrin signaling, In: Gutkind J.S. (Ed), Signalling Networks and Cell Cycle Control. Humana Press, Totowa NJ., 2000, pp. 1-25.

10. Parsons J.T., Focal adhesion kinase: the first ten years. J. Cell Sci. 15: 1409-1416, 2003.

11. Mitra S.K., Hanson D.A. and Schlaepfer D.D., Focal adhesion kinase: in command and control of cell motility. Nat. Rev. Mol. Cell Biol. 6: 56-68, 2005.

12. Hatai M., Hashi H., Mogi A., Soga H., Yokota J. and Yaoi Y., Stimulation of tyrosine- and serine-phosphorylation of focal adhesion kinase in mouse $3 \mathrm{~T} 3$ cells by fibronectin and fibroblast growth factor. FEBS Lett. 350: 113-116, 1994.

13. Rankin S. and Rozengurt E., Platelet-derived growth factor modulation of focal adhesion kinase (p125FAK) and paxillin tyrosine phosphorylation in Swiss 3T3 cells. Bellshaped dose response and cross-talk with bombesin. J. Biol. Chem. 269: 704-710, 1994.

14. Chen H.C., Chan P.C., Tang M.J., Cheng C.H. and Chang T.J., Tyrosine phosphorylation of focal adhesion kinase stimulated by hepatocyte growth factor leads to mitogenactivated protein kinase activation. J. Biol. Chem. 273: 25777-25782, 1998.

15. Sieg D.J., Hauck C.R., Ilic D., Klingbell C.K., Schaefer E., Damsky C.H. and Schlaepfer D.D., FAK integrates growth-factor and integrin signals to promote cell migration. Nat. Cell Biol. 2: 249-256, 2000.

16. Bardelli A., Pugliese L. and Comoglio P.M., "Invasivegrowth" signaling by the Met/HGF receptor: the hereditary renal carcinoma connection. Biochem. Biophys. Acta 1333: M41-M51, 1997 (Review on Cancer).

17. Birchmeier C. and Gherardi E., Developmental roles of $\mathrm{HGF} / \mathrm{SF}$ and its receptor, the c-Met tyrosine kinase. Trends Cell Biol. 8: 404-410, 1998.

18. Birchmeier C., Birchmeier W., Gherardi E. and Vande Woude G.F., Met, metastasis, motility and more. Nat. Rev. Mol. Cell Biol. 4: 915-925, 2003.

19. Bottaro D.P., Rubin J.S., Faletto D.L., Chan A.M.L., Kmiecik T.E., Vande Woulde G.F. and Aaronson S.A., Identification of the hepatocyte growth factor receptor as the c-met proto-oncogene product. Science 251: 802-804, 1991.

20. Giordano S., Ponzetto C., Di Renzo M.F., Cooper C.S. and Comoglio P.M., Tyrosine kinase receptor indistinguishable from the c-met protein. Nature 339: 155-158, 1989.

21. Rodrigues G.A., Naujokas M.A. and Park M., Alternative splicing generates isoforms of the met receptor tyrosine kinase which undergo differential processing. Mol. Cell Biol. 11: 2962-2970, 1991.

22. Naldini L., Vigna E., Narsimhan R.P., Gaudino G., Zarnegar R., Michalopoulos G.A. and Comoglio P.M., Hepatocyte growth factor (HGF) stimulates the tyrosinase kinase activity of the receptor encoded by the protooncogene c-MET. Oncogene 6: 501-504, 1991.

23. Ferracini R., Longati P., Naldini L., Vigna E. and Comoglio P.M., Identification of the major autophospho- rylation site of the Met/hepatocyte growth factor receptor tyrosine kinase. J. Biol. Chem. 266: 19558-19564, 1991.

24. Weidner K.M., Sachs M. and Birchmeier W., The Met receptor tyrosine kinase transduces motility, proliferation, and morphogenic signals of scatter factor/ hepatocyte growth factor in epithelial cells. J. Cell. Biol. 121: 145-154, 1993.

25. Zhu H., Naujokas M.A., Fixman E.D., Torossian K. and Park M., Tyrosine 1356 in the carboxyl-terminal tail of the $\mathrm{HGF} / \mathrm{SF}$ receptor is essential for the transduction of signals for cell motility and morphogenesis. J. Biol. Chem. 269: 29943-29948, 1994.

26. Weidner K.M., Di Cesare S., Sachs M., Brinkmann V., Behrens J. and Birchmeier W., Interaction between Gab1 and the c-met receptor tyrosine kinase is responsible for epithelial morphogenesis. Nature 384: 173-176, 1996.

27. Sachs M., Brohmann H., Zechner D., Muller T., Hulsken J., Walther I., Schaeper U., Birchmeier C. and Birchmeier W., Essential role of Gab1 for signaling by the c-Met receptor in vivo. J. Cell Biol. 150: 1375-1384, 2000.

28. Ponzetto C., Bardelli A., Zhen Z., Maina F., dalla Zonca P., Giordano S., Graziani A., Panayotou G. and Comoglio P.M., A multifunctional docking site mediates signaling and transformation by the hepatocyte growth factor/scatter factor receptor family. Cell 77: 261-271, 1994.

29. Pelicci G., Giordano S., Zhen Z., Salcini A.E., Lanfrancone L., Bardelli A., Panayotou G., Waterfield M.D., Ponzetto C., Pelicci P.G. and Comoglio P.M., The motogenic and mitogenic responses to $\mathrm{HGF}$ are amplified by the Shc adaptor protein. Oncogene 10: 1631-1638, 1995.

30. Trusolino L., Bertotti A. and Comoglio P.M., A signaling adapter function for $\alpha 6 \beta 4$ integrin in the control of HGF-dependent invasive growth. Cell 107: 643-654, 2001.

31. Falcioni R., Antonini A., Nistico P., Stefano S., Crescenzi M., Natali P.G. and Sacchi A., $\alpha 6 \beta 4$ and $\alpha 6 \beta 1$ integrins associate with ErbB-2 in human carcinoma cell lines. Exp. Cell Res. 236: 76-85, 1997.

32. Gambaletta D., Marchetti A., Bebedetti L., Mercurio A.M., Sacchi A. and Falcioni R., Cooperative signaling between $\alpha 6 \beta 4$ integrin and ErbB-2 receptor is required to promote phosphatidylinositol 3-kinase-dependnet invasion. J. Biol. Chem. 275: 10604-10610, 2000.

33. Sunberg C. and Rubin K., Stimulation of betal integrins on fibroblasts induces PDGF independent tyrosine phosphorylation of PDGF beta-receptors. J. Cell Biol. 132: 741-752, 1996.

34. Wang R., Kobayashi R. and Bishop J.M., Cellular adherence elicits ligand-independent activation of the Met cell-surface receptor. Proc. Natl. Acad. Sci. U.S.A. 93: 8425-8430, 1996

35. Moro L. and Venturino M., Integrins induce activation of EGF receptor: role in MAP kinase induction and adhesiondependent cell survival. EMBO J. 17: 6622-6632, 1998.

36. Danilkovitch-Miagkova A., Angeloni D., Skeel A., Donley S., Lerman M. and Leonard E.J., Integrin-mediated RON growth factor receptor phosphorylation requires tyrosine kinase activity of both the receptor and c-Src. J. Biol. Chem. 275: 14783-14786, 2000.

37. Wang J.F., Zhang X.F. and Groopman J.E., Stimulation of beta 1 integrin induces tyrosine phosphorylation of vascular endothelial growth factor receptor-3 and modulates cell migration. J. Biol. Chem. 276: 41950-41957, 2001.

38. Wang R., Ferrell L.D., Faouzi S., Maher J.J. and Bishop J.M., Activation of the Met receptor by cell attachment 
induces and sustains hepatocellular carcinomas in transgenic mice. J. Cell Biol. 153: 023-1033, 2001.

39. Moro L., Dolce L., Cabodi S., Bergatto E., Erba E.B., Smeriglio M., Turco E., Retta S.F., Giuffrida M.G., Venturino M., Godovac-Zimmermann J., Conti A., Schaefer E., Beguinot L., Tacchetti C., Gaggini P., Silengo L., Tarone G. and Defilippi P., Integrin-induced epidermal growth factor (EGF) receptor activation requires c-Src and p130Cas and leads to phosphorylation of specific EGF receptor tyrosines. J. Biol. Chem. 277: 9405-9414, 2002.

40. Trusolino L., Serini G., Cecchini G., Besati C., Ambesi-Impiombato F.S., Marchisio P.C. and De Filippi R., Growth factor-dependent activation of integrin $\alpha \mathrm{v} \beta 3$ in normal epithelial cells: implications for tumor invasion. J. Cell Biol. 142: 1145-1156, 1998.

41. Rahman S., Patel Y., Murray J., Patel K.V., Sumathipala R., Sobel M. and Wijelath E.S., Novel hepatocyte growth factor (HGF) binding domains on fibronectin and vitronectin coordinate a distinct and amplified Met-integrin induced signaling pathway in endothelial cells. BMC Cell Biol. 6: 8, 2005.

42. Mine S., Tanaka Y., Suematu M., Aso M., Fujisaki T., Yamada S. and Eto S., Hepatocyte growth factor is a potent trigger of neutrophil adhesion through rapid activation of lymphocyte function-associated antigen-1. Lab. Invest. 78: 1395-1404, 1998.

43. Fujisaki T., Tanaka Y., Fujii K., Mine S., Saito K., Yamada S., Yamashita U., Irimura T. and Eto S., CD44 stimulation induces integrin-mediated adhesion of colon cancer cell lines to endothelial cells by up-regulation of integrins and c-Met and activation of integrins. Cancer Res. 59: 4427-4434, 1999.

44. Weimar I.S., de Jong D., Muller E.J., Nakamura T., van Gorp J.M., de Gast G.C. and Gerritsen W.R., Hepatocyte growth factor/scatter factor promotes adhesion of lymphoma cells to extracellular matrix molecules via alpha 4 beta 1 and alpha 5 beta 1 integrins. Blood 89: 990-1000, 1997.

45. van der Voort R., Taher T.E., Keehnen R.M., Smit L., Groenink M. and Pals S.T., Paracrine regulation of germinal center B cell adhesion through the c-met-hepatocyte growth factor/scatter factor pathway. J. Exp. Med. 185: 2121-2131, 1997.

46. Pietrapiana D., Sala M., Prat M. and Sinigaglia F., Met identification on human platelets: role of hepatocyte growth factor in the modulation of platelet activation. FEBS Lett. 579: 4550-4554, 2005.

47. Lai J.F., Kao S.C., Jiang S.T., Tang M.J., Chan P.C. and Chen H.C., Involvement of focal adhesion kinase in hepatocyte growth factor-induced scatter of Madin-Darby kidney cells. J. Biol. Chem. 275: 7474-7480, 2002.

48. Chan P.C., Liang C.C., Yu K.C., Chang M.C., Ho W.L., Chen B.H. and Chen H.C., Synergistic effect of focal adhesion kinase overexpression and hepatocyte growth factor stimulation on cell transformation. J. Biol. Chem. 277: 50373-50379, 2002.

49. Weiner T.M., Liu E.T., Craven R.J. and Cance W.G., Expression of focal adhesion kinase gene and invasive cancer. Lancet 342: 1024-1025, 1993.

50. Owens L.V., Xu L., Craven R.J., Dent G.A., Weiner T.M., Knornberg L., Liu E.T. and Cance W.G., Overexpression of the focal adhesion kinase ( $125^{\mathrm{FAK}}$ ) in invasive human tumors. Cancer Res. 55: 2752-2755, 1995.
51. Agochiya M., Brunton V.G., Owens D.W., Parkinson E.K., Paraskeva C., Keith W.N. and Frame M.C., Increased dosage and amplification of the focal adhesion kinase gene in human cancer cells. Oncogene 18: $5646-5653,2000$.

52. Liang C.C. and Chen H.C., Sustained activation of extracellular signal-regulated kinase stimulated by hepatocyte growth factor leads to integrin $\alpha 2$ expression that is involved in cell scattering. J. Biol. Chem. 276: 21146-21152, 2001.

53. Chiu S.J., Jiang S.T., Wang Y.K. and Tang M.J., HGF upregulates $\alpha 2 \beta 1$ integrin in MDCK cells: implications in tubulogenesis. J. Biomed. Sci. 9: 261-272, 2002.

54. Robinson M.J. and Cobb M.H., Mitogen-activated protein kinase pathways. Curr. Opin. Cell Biol. 9: 180-186, 1997.

55. Marshall C.J., Specificity of receptor tyrosine kinase signaling: transient versus sustained extracellular signalregulated kinase activation. Cell 80: 179-185, 1995.

56. York R.D., Yao H., Dillon T., Ellig C.L., Eckert S.P., McCleskey E.W. and Stork P.J., Rap1 mediates sustained MAP kinase activation induced by nerve growth factor. Nature 392: 622-626, 1998.

57. McCawley L.J., Li S., Wattenberg E.V. and Hudson L.G., Sustained activation of the mitogen-activated protein kinase pathway. J. Biol. Chem. 274: 4347-4353, 1999

58. Tanimura S., Nomura K., Ozaki K., Tsujimoto M., Kondo T. and Kohno M., Prolonged nuclear retention of activated extracellular signal-regulated kinase $1 / 2$ is required for hepatocyte growth-induced cell motility. J. Biol. Chem. 277: 28256-28264, 2002.

59. Maroun C.R., Naujokas M.A., Holgado-Madruga M., Wong A.J. and Park M., The tyrosine phosphatase SHP-2 is required for sustained activation of extracellular signalregulated kinase and epithelial morphogenesis downstream from the Met receptor tyrosine kinase. Mol. Cell Biol. 20: 8513-8525, 2000.

60. Saelman E.U.M., Keely P.K. and Santoro S.A., Loss of MDCK cell $\alpha 2 \beta 1$ integrin expression results in reduced cyst formation, failure of hepatocyte growth factor/scatterinudced branching morphogenesis, and increased apoptosis. J. Cell Sci. 108: 3531-3540, 1995.

61. Jiang S.T., Chiu S.J., Chen H.C., Chuang W.J. and Tang M.J., The role of $\alpha 3 \beta 1$ integrin in tubulogenesis of MDCK cells. Kidney Int. 59: 1770-1778, 2001.

62. Zutter M.M., Santoro S.A., Painter A.S., Tsung Y.L. and Gafford A., The human alpha 2 integrin gene promoter. Identification of positive and negative regulatory elements important for cell-type and developmentally restricted gene expression. J. Biol. Chem. 269: 463-469, 1994.

63. Zutter M.M., Ryan E.E. and Painter A.D., Binding of phosphorylated Spl protein to tandem Sp1 binding sites regulates alpha2 integrin gene core promoter activity. Blood 90: 678-689, 1997.

64. Angel P., Hattori K., Smeal T. and Karin M., The jun proto-oncogene is positively autoregulated by its product, Jun/AP-1. Cell 55: 875-885, 1988.

65. Chiu R., Boyle W.J., Meek J., Smeal T., Hunter T. and Karin M., The c-Fos protein interacts with c-Jun/AP-1 to stimulate transcription of AP-1 responsive genes. Cell 54: 541-552, 1988.

66. Merchant J.L., Du M. and Todisco A., Sp1 phosphorylation by Erk 2 stimulates DNA binding. Biochem. Biophys. Res. Commun. 254: 454-461, 1999. 
67. Howe A.K. and Juliano R.L., Distinct mechanisms mediate the initial and sustained phases of integrin-mediated activation of the $\mathrm{Raf} / \mathrm{MEK} /$ mitogen-activated protein kinase cascade. J. Biol. Chem. 273: 27268-27274, 1998.
68. Murphy L.O., Smith S., Chen R.H., Fingar D.C. and Blenis J., Molecular interpretation of ERK signal duration by immediate early gene products. Nat. Cell Biol. 4: 556564, 2002. 